\title{
ЖЕРТВА И ЖЕРТВЕННОСТЬ В СВЕТСКОЙ И ХРИСТИАНСКОЙ ЭТИКЕ
}

\section{SACRIFICE AND VICTIMHOOD IN SECULAR AND CHRISTIAN ETHICS \\ O. Pugachev \\ N. Pugacheva}

Summary: The article is devoted to the analysis of the concepts of sacrifice and victimhood in Christian theology and secular ethics, as well as in Christian ethics, which occupies an intermediate position between them. Shows the moral and historical significance of sacrificial acts, regardless of faith. In addition, possible moral distortions of sacrifice and selfsacrifice are considered. The self-sacrifice is interpreted, inter alia, in the aspect of Kant's autonomous ethics.

Keywords: sacrifice, victimhood, self-sacrifice, Christian ethics, I. Kant, G. Marcel.

\author{
Пугачев Олег Сергеевич \\ Д.ф.н., профессор, Пензенский государственный \\ аграрный университет \\ oleg_pugachev@mail.ru \\ Пугачева Наталья Петровна \\ К.фр.н., дочент, Пензенский государственный \\ аграрный университет \\ kozlova_natalya@list.ru
}

Аннотация: Статья посвящена анализу понятий жертвы и жертвенности в христианском богословии и светской этике, а также в этике христианской, занимающей промежуточное положением между ними. Показывается нравственная и историческая значимость жертвенных поступков, независимо от веры. Кроме того, рассматриваются возможные нравственные искажения жертвенности и самопожертвования. Последнее трактуется, в том числе, в аспекте автономной этики Канта.

Ключевые слова: жертва, жертвенность, самопожертвование, христианская этика, И. Кант, Г. Марсель.

Симеона Нового Богослова. Если в западной Европе анагогия как метод утвердилась в Средние века (сочинения Беды Достопочтенного, Данте Алигьери), то в России это произошло позднее, в середине XVI века. В этой связи, необходимо назвать имена Максима Грека, Дмитрия Герасимовича. Главным же понятием богословско-философской мысли в России анагогия становится во второй половине XVII в. и в первой половине XIX в. (св. Тихон Задонский; св. Паисий Величковский, св. Филарет Московский, Платон (Левшин)) [3; С. 12].

Несмотря на явственные отличия различных уровней понимания, их объединяет нахождение в русле единой христианской догматики. Поэтому большое значение всегда имела проповедническая деятельность наряду со сложнейшими теологическими построениями.

Анализ христианской этики в аспекте жертвы и жертвенности в их житейском, практическом плане, можно начать, обратившись к не столь далекому прошлому деятельности православного священства второй половины XIX века. В качестве примера приведем журнал «Руководство для сельских пастырей», который издавался при Киевской духовной семинарии. В частности, текст «Поучения о том, что воин христианин должен делать перед сражением, во время сражения и что значит кончина воина на поле битвы» [5]. Как видно из названия тема поучения как нельзя конкретна и остра. Священник начинает свое поучение с мысли о том, что христолюбивый воин перед битвой с врагами о многом должен позаботиться и подумать, особенно в свете того, что каждый 
может предстать на суд Божий, если Господь определит кому-то погибнуть в бою. Нужно, идя в сражение, очистить душу покаянием, примириться с теми, с кем имел вражду, попросить прощения у обиженных. Самая главная обязанность воина - это повиноваться начальству: тем более это необходимо на поле брани.

Главная идея поучения в том, что все мы - дети одного Отца небесного и в мирное время нужно относится к другим народам дружественно. Они только тогда становятся врагами, когда выступают против нас с орудием в руках. Но если во время войны заключено перемирие, то здесь тоже нет оснований для враждебных чувств. «Во время самого сражения, - говорит проповедник, - если велят, нужно нападать; но надо знать на кого нападать; надо нападать на войско, но не трогать мирных жителей и даже в ряду неприятельского войска не следует нападать на священников, лекарей, сестер милосердия, так как эти люди не владеют оружием, а нападать на безоружного бесчестно для воина» [5; С. 286].

Далее в своем поучении священник Иоанн Недешев призывает воинов не страшиться смерти на поле брани, поскольку это кровь, пролитая «за братий, за Царя и Отечество», и она будет залогом милосердия Божия к погибшим в прощении им грехов. Мы можем сказать, отвлекшись от религиозного содержания проповеди, что основные положения в ней мало чем отличаются от требований воинского устава и присяги многих армий, где служат люди нехристианских конфессий. В чем же необычность? Отвечая на этот вопрос, мы должны обратиться к самому этическому фундаменту, на котором основано данное поучение. Вот он: принеся себя в жертву за друзей-сослуживцев; за веру Христову, за Отечество, воин христианский делает это сознательно из той жертвенной Любви, о которой говорил ап. Павел (1 Кор. 13); из той любви, которая способна уподобить солдатскую жертвенность христовой жертвенности. В этом поучении автор показывает сопряжение конкретно-данного события, когда человек находится в «пограничной ситуации» (К. Ясперс), когда в лицо ему смотрит смерть, и абсолютного события: смерти и воскресения Спасителя. Мы знаем из истории нашей страны, сколь многочисленными были жертвенные подвиги «за други своя» наших воинов. Но и в наши дни жертвенность также составляет особую сторону отличия среди солдат.

Сегодняшний же день, который характеризуется всемирным бедствием под названием «ковид», пандемией, продолжает выявлять истинно жертвенное служение врачей-христиан и не-христиан; православных и неправославных, но одинаково вдохновленных примером нравственных дел и подвигов на благо ближнего и дальнего. Следует сказать и о роли православного священства, которое в этот период, также не щадя ни сил, ни времени, ни средств, делает все возможное для под- держания духа мирян.

В сети интернет на «Православном портале» однажды прозвучал вопрос: «Зачем Богу жертвы?» На этот вопрос отвечал митрополит Илларион, который, в частности, указал на то, что Бог в жертвах нужды не имеет, поскольку он, по мысли богословов, существо самодостаточное. Не все теологи Православной Церкви разделяют мнение о том, что жертва Христа была принесена Богу Отцу с тем, чтобы воздать эквивалентное Его правосудию. «Наверное, - пишет автор, - правильнее всего сказать, что крестная жертва была нужна не Богу Отцу, а нам с вами. Именно так говорит святитель Григорий Богослов - автор IV века: “Нам, чтобы ожить, необходим Бог воплотившийся и умерщвленный". То есть крестная жертва была нужна не Богу Отцу, а нам, во искупление наших грехов. И мы приобщаемся к плодам этой жертвы, когда принимаем крещение, когда участвуем в церковных таинствах и когда исполняем заповеди Господа нашего Иисуса Христа» [2].

Но в светской этике, «свободной» от богословских рассуждений, мы также находим тему жертвы и жертвенности. Особенно ярко это выражено в тезисе о самопожертвовании. Здесь необходимо сделать некоторое историческое отступление в том смысле, что изначально, исконно (или, как теперь часто принято в языке науки - «примордиально») жертва, жертвоприношение содержали чисто культовый смысл и в этой связи их нужно понимать генетически соприродными с чувством священного, святого, что получило в религиоведении XX века наименование «нуминозного» [7].

Имея это ввиду, мы вправе предположить, что для светского, индифферентного к религии или прямо атеистического, сознания понятия жертвы и жертвенности являются чаще всего привнесенными, а заодно и модифицированными в том отношении, что из них убрано их первоначально религиозное содержание. Чем же оно заменено? Кто же поставлен на место первобытных языческих богов или единого Бога? Не трудно догадаться: это человек или собирательное человечество. Как же стала пониматься жертва и жертвенность? Жертва в светской жизни стала означать более-менее стесненное существование, к которому человек приговаривает себя сам или становится пассивным объектом чьих-то манипуляций. Так, например, мы имеем понятия о жертвах кораблекрушения (и ряда других катастроф) и о самопожертвовании героя, закрывшего своим телом амбразуру дота или дзота.

Современный человек, замкнувшийся в оболочке индивидуального и личностно обособленного «Я» понимает самопожертвование как принесение своих интересов, их сознательное ущемление на пользу обществу или какому-либо другому человеку, партии, организации и 
т.п. В отношении патриотического пафоса самопожертвование во имя процветания родины или ее защиты, спасения, придает личности ореол святости уже за пределами чисто фискальных, корпоративных и личностных амбиций. Здесь как бы разрушается демаркационная линия между тем, что считается святым и освященным в светском смысле, и тем, что четко определено в той или иной религиозной конфессии как божественное, святое. Иными словами - светское чувство на некоторых высотах своего подъема волей-неволей обращается к религии и в ней находит успокоение и удовлетворение своих духовных запросов. Иногда это происходит и через философию как среднюю ступень.

Но если высокое понятие о жертве и жертвенности в светском понятийном этическом поле можно унифицировать, то совсем иное дело - низшие проявления данного феномена. Так, например, всяким, в том числе и рациональным, ограничениям собственной лености, дурных привычек и прочего придается характер жертвенности и самопожертвования. То же самое относится к сознательному лишению себя комфортных условий жизни или психологических состояний. Бабушка, находящаяся на пенсии, жертвует собой, собственным своим индивидуальным личным временем для того, чтобы выполнить просьбу дочери: посидеть какое-то время с внуками. Дедушка отказывается от запланированной лыжной прогулки с друзьями ради той же цели - уделить время внукам. Конечно, что касается конкретно внуков, то здесь существует и принудительная моральная и правовая необходимость, которая, действуя с силой законности, настаивает на исполнении должного, необходимого с социальной точки зрения в ущерб, однако, и в ущемление, ограничение личной свободы.

Можем ли мы оценить такую вот «жертвенность» только иронически, минуя скрытые в ней переплетения сложных психологических переживаний, установок и комплексов? Важно увидеть за кажущейся жертвенностью не только ее истинное значение, но и механизмы, вскрывая и изучая которые мы могли бы понять субъективное их значение и построение. Так, например, далеко не всякий отказ бабушек и дедушек (внешне вполне здоровых и благополучных) посвятить часть своего личного времени внукам является чем-то негативным в этическом или правовом смысле.

Рассмотрим ситуацию, так сказать, в обратной перспективе. Зачастую молодые люди, образуя семью, заранее планируют своих родителей в прямые кандидаты в няньки и заодно воспитатели их собственных детей. Тем самым отказываясь отчасти от своих детей, ничем не жертвуя им ни в обыденном, ни в духовном смысле. И спустя время раскаяние в этом может привести и к жертвенности: жертвенности любви.
Любовь является основой христианской жертвенности. Это та любовь, о которой свидетельствовал апостол Павел: «Любовь долготерпит, милосердствует, любовь не завидует, любовь не превозносится, не гордится, не бесчинствует, не ищет своего, не раздражается, не мыслит зла, не радуется неправде, а сорадуется истине» (1 Кор. 13:4-7).

В статье Валерия Духанина «О жертве, жертвенности и ее пределах» [1] красной нитью проводится мысль о том, что именно любовь побуждает человека к жертвенному поступку. Автор приводит примеры «холодной жертвенности», когда она понимается в том смысле, что человек отдает, отрывает от себя нечто весьма для него важное. И поскольку так происходит, он считает свою «жертвенность» вполне достаточной, чтобы «откупиться» от ближнего или дальнего, чтобы в подобных поступках не было и отзвука любви.

В подобных случаях проскальзывает намек на автономную этику великого немецкого философа Иммануила Канта. Кант считал, что человеческие поступки только иногда можно считать моральными, нравственными, когда они совершаются индивидом незаинтересованно, когда в их мотивации отсутствуют какие-либо симпатии и антипатии, предпочтения или эмоции. Они должны совершаться из чувства долга. Поэтому морально в данном случае поступает тот, кто, испытывая к предмету своего действия в области нравственности ненависть, все же поступает по отношению к нему в соответствии с требованиями морального закона: «Поступай с другими так, чтобы твой поступок мог бы вписываться в общую структуру нравственных норм и был бы приемлем его стороны других людей, общества, т.е. всех». Простая версия этого «золотого правила» хорошо известна: «Поступай с другими так, как ты хотел бы, чтобы люди поступали с тобой».

Мы не будем здесь обсуждать все этические и общефилософские моменты этики Канта, но ясно одно, что в ней весьма близко стоят такие позиции как долженствование и жертвенность. Это ригористическая этика и ее ригоризм вытекает, в частности, из желания разделить сферы этического и религиозного. Это попытка обосновать этику вне и помимо религии. Удалось ли это Канту? Отвечая на этот вопрос, мы могли бы вкратце напомнить, что, обосновывая нравственные принципы и главный из них как моральный закон, Кант обратился к постулату свободы, но она для своего существования и реализации нуждается в других принципах, которые философ тоже «постулирует», как не требующие доказательства и очевидно необходимые: это Бог и бессмертие души. Таким образом, добиваясь самозаконности морали, немецкий философ без Бога и религии обойтись не смог.

Вернемся к вышеупомянутой статье, поскольку она 
затрагивает социально-психологические аспекты жертвы и жертвенности. Поставив прямой вопрос: всегда ли мы способны на жертвенность? Всякая ли жертва нам по плечу? Автор бескомпромиссно рисует следующую картину, важность которой объясняет обширность цитаты: «Понимая, что надо жить по евангельским заповедям, христианин соглашается помочь ближнему в определенных проблемах. Пытаясь участвовать в жизни ближнего, он берет на себя нагрузки, связанные с заботой о нем. Чувствуя, что мера этих нагрузок в определенный момент становится для него непосильной, христианин загоняет свое недовольство внутрь себя, думая, что надо терпеть, исполняя заповедь. Поднатужившись еще немного, он все равно не выдерживает... Безрассудно принятые себя непосильные нагрузки способны довести до озверения. Ноша, взятая не по плечу, делает сердце равнодушным, холодным и жестким. Итог - не христианская жертвенность, равнозначная бескорыстной любви, которая не ждет за свое добрые дело даже обыкновенного "спасибо", а злоба, психотравмирующая личность и вносящая дисбаланс в жизнь» [1].

Перед нами психологически очень точная характеристика нас самих, когда мы воображаем себя способными в корне изменить мир вокруг себя или дать бесконечное счастье любимым и ближним. Безусловно, неблагодарность, особенно в случае жертвенности со стороны благотворителя - дело плохое, и Кант относил это явление к грехам самым тяжелым, именуя их «дьявольскими». И тут надо быть очень осторожным, чтобы не попасть в зависимость от ожидания похвалы и добра за свои жертвенные поступки. Здесь человека может ждать полное разочарование: большинство людей, в том числе и верующие, воспринимают чужое добро по отношению к ним как «нужное», заслуженное, так сказать, неким уже заранее определенным ими самими собственным статусом. Так эгоизм и эгоцентризм принимают как грубые, так и довольно утонченные формы.

Автор статьи, говоря о том, что, согласно заповеди «когда творишь милостыню, пусть левая рука твоя не знает, что делает правая» (Мф.6:3), делает вывод о том, что, делая людям добро, не нужно стремиться превратить их в своих «должников», поэтому, с нравственной точки зрения, правильным будет считать: то, что сделано в перспективе ответного добра и благодарности, теряет свою бескорыстную основу и превращается в бремя для тех, кому оказана помощь и тому подобные блага.

Христианская этика имеет существенные отличия от светской, которая, в делании людям добра все же полагается на адекватный ответ: евангельские заповеди задают более высокую нравственную градацию. Вспомним, хотя бы о знаменитой лепте вдовы. Именно имея особую любовь в сердце, вдова пожертвовала свои скудные средства, оставив себя без пропитания. Но и простое по- жертвование без любви, как учат Отцы церкви, приучает душу человеческую чувствовать добро и деятельно участвовать в нем.

Мы уже видели, что в христианстве жертвенность вне любви к Богу и людям (в том числе - и врагам) не может иметь той полноты и смысла, каким субъективно ее хотел бы наделить человек светский, руководствующийся только рациональностью научного типа. Легко заметить, что даже внерелигиозная этика, полагающая свои основания в доисторической и исторической ретроспективе человеческого бытия в космосе и на Земле, не способна, исходя из собственно научных положений, объяснить то, что разумеется как бы само собой, но, тем не менее, составляет вовсе не общедоступную феноменологию действия: как, например, человек, не умеющий плавать, бросается спасать тонущего ребенка?

И таких ситуаций «абсурда», выходящих за пределы так называемого «здравого смысла», достаточно много. Ведь даже в простых жизненных ситуациях та же любовь между мужчиной и женщиной часто возникает не в силу каких-то «заслуг» одного перед другим, а вопреки, даже при отсутствии каких-то качеств, которые кому-то, скажем - родителям - кажутся необходимыми и долженствующими быть в наличии (ум, красота, обеспеченность, порядочность и т.п.). Таким образом, наши чувства, аффекты, зачастую перекрывают многие логически верные построения и могут привести к различным последствиям. В этом свете, наша нравственная жизнь протекает так, что мы постоянно чем-то посильно жертвуем - собственным комфортом, здоровьем, материальным благополучием.

В то же время нельзя обойти вниманием и те искажения, которые подстерегают не только неверующего человека, но и верующего на пути жертвенного служения. Так, например, довольно подробно рассматривается искаженность любви в книге протоирея Владислава Свешникова «Очерки христианской этики» [4]. Здесь автор, в частности, пишет: «Порою искаженность, отчасти и жертвенная, встречается и вовсе в психопатическом и одновременно нравственно-философском варианте любви к “дальним»" без любви к “ближним". Это - “любовь" социалистически извращенная» [4; С. 522].

Как известно, вера, надежда и любовь рассматриваются в христианстве в качестве добродетелей, посредством наличия и исполнения которых мы некоторым образом познаем выполняем евангельские заветы.

Взаимосвязь таких психологических феноменов и одновременно этико-религиозных добродетелей, каковыми являются истина, надежда, справедливость, сострадание и другие - нашла отражение и в творчестве видных мыслителей Запада XX-XXI вв. Остановим вни- 
мание, например, на личности французского религиозного философа Г. Марселя. В своей книге «Homo viator. Пролегомены к метафизике надежды» (издана в Париже в 1944 г., русский перевод опубликован в 1998 г.) он утверждает мысль о недопустимости такой ситуации «когда метафизика веры возникает на руинах гуманизма» [6]. Французский теолог и философ в своем синтезе объединил два аспекта восприятия мира: а) христианский мир благодати и б) философский мир вопрошания. Среди ценностей мира Марсель выделял «мужество и жертвенность в сочетании с духом истины...». Жертвенность можно понимать и с точки зрения милосердия, открытости человека навстречу другим людям, готовности по- мочь им, способности превратить условия внешней ситуации во внутренний процесс духовной деятельности.

Отличие этики христианской от этики светской, нерелигиозной, состоит в абсолютном и всецелом подчинении всех культурных, нравственных, материальных, духовных ценностей и отношений Богу как их Творцу. Отсюда же выводится и определенная иерархия ценностей. Однако нет никаких причин преуменьшать нравственную и историческую значимость жертвенного подвига в любом его выражении, будь то высокие примеры светской жертвенности или жертвенность христиан-мучеников.

\section{ЛИТЕРАТУРА}

1. Духанин В. 0 жертве, жертвенности и ее пределах [Электронный ресурc]. URL: https://pravoslavie.ru/60235.html (дата 0бращения 10.09.2021).

2. Зачем Богу жертвы [Электронный ресурс]. URL: https://jesus-portal.ru/life/otvety-pastyrya/zachem-bogu-zhertvy/ (дата 0бращения 10.09.2021).

3. Калитин П.Н. Анагогия // Словарь философских терминов. - М.: ИНФРА - М, 2005. - С. 12.

4. Свешников В. Очерки христианской этики. - М.: Паломник, 2000. - 624 с.

5. Свящ. Иоанн Недешев. Поучение о том, что воин христианин должен делать перед сражением, во время сражения и что значит кончина воина на поле битвы // Руководство для сельских пастырей. - Т. 2. - № 26. - Киев, 1871. - С. 285-287.

6. Тавризян Г.М. «Homo viator. Пролегомены к метафизике надежды» // Этика: Энциклопедический словарь / Под ред. Р.Г. Апресяна и А.А. Гусейнова. М.: Гардарики, 2001. - С. 90.

7. Энциклопедия эпистемологии и философии науки [Электронный ресурс]. URL: https://epistemology_of_science.academic.ru/ (дата 0бращения 10.09.2021)

(c Пугачев Олег Сергеевич (oleg_pugachev@mail.ru), Пугачева Наталья Петровна (kozlova_natalya@list.ru).

Журнал «Современная наука: актуальные проблемы теории и практики»

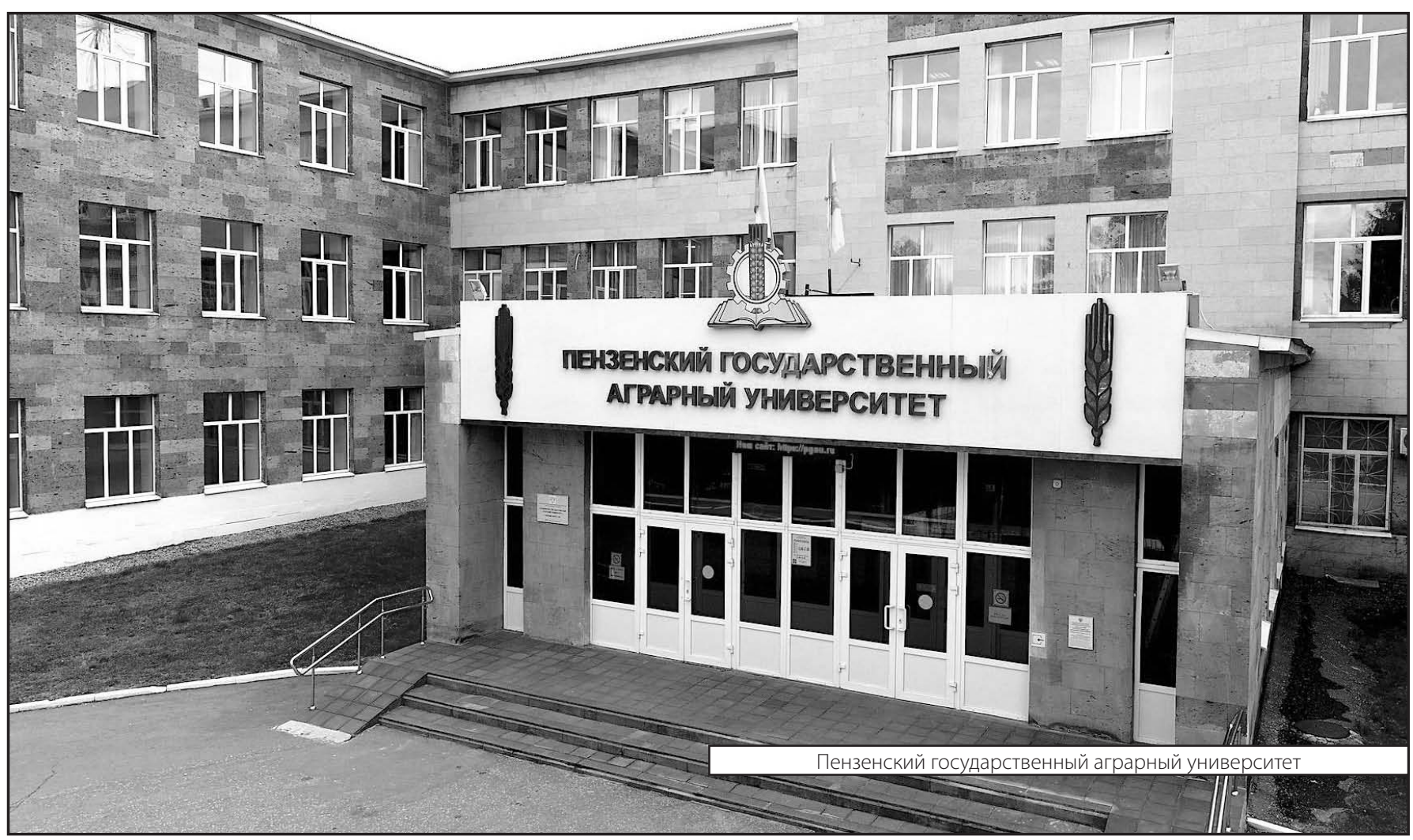

